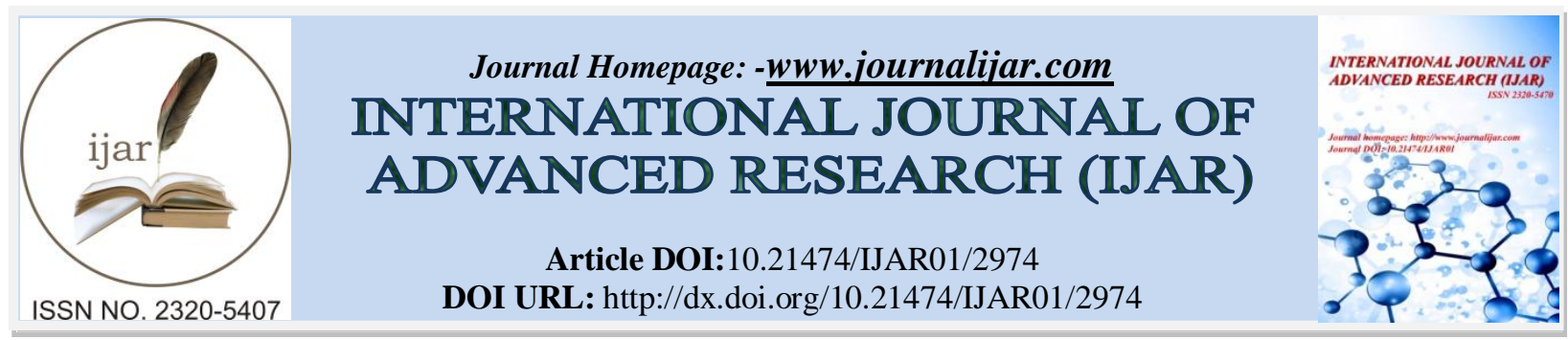

RESEARCH ARTICLE

\title{
PHYSICAL ACTIVITI AMONG MEDICAL STUDENTS OF IMAM UNIVERSISTY AND ITS EFFECT ON THEIR ACADEMIC PERFORMANCE
}

Algarni Ali and Aldughaytheir Mohammed.

Al Imam Mohammad Ibn Saud Islamic University (IMSIU), Saudi Arabia.

\section{Manuscript Info}

Manuscript History

Received: 26 November 2016

Final Accepted: 27 December 2016

Published: January 2017

Key words:-

Physical activity, GPA , Academic

performance, medical students.

\begin{abstract}
Introduction:Physical activity is defined as any bodily movement produced by the skeletal muscles that results in energy expenditure above the basal level, it is an important factor in improving the quality of life and preventing some medical condition. Many studies have shown that a regular physical activity increases thinking and learning skills

Objectives:The purpose of this study is to determine the percentage of students who are physically active and to find out whether physical activity has a beneficial effect on their academic performance or not.

Materials \&methods:a cross-sectional surveydistributed to all the medical students of Imam university. We used the GPA and duration of daily studying to access the academic performance. Type and duration of physical activity were used to access the level of physical activity of the participants. We received 87 complete survey with a response rate of $18.5 \%$.

Results:29 students out of all participant were physically active, most of the student who were physically active had a GPA of 3.00 to 3.99 ( 18 students) followed by the students who scored a GPA of 4.00 to 5.00 (7 students ). Most of the students who were physically active spent more than 180 minutes of physical activity weekly (37.9\%).We found that there was an association between physical activity and academic performance with a statistical trend toward significance $(\mathrm{p}$ value $=0.09$ ).

Conclusions:We found that students with a higher GPA tend to be more physically active than students with lower GPA. We recommend doing a similar study on a larger scale to determine the effect of physical activity on academic performance in the Kingdom of Saudi Arabia.
\end{abstract}

Copy Right, IJAR, 2016,. All rights reserved.

\section{Introduction:-}

Physical activity is an important factor in improving the quality of life and preventing some medical conditions, it increases the strength of bones and muscle, reduces the cardiovascular risk and its associated with lower risk of developing diabetes mellitus type 2 and metabolic syndromes. [1,2] Physical activity is defined as any bodily movement produced by the skeletal muscles that results in energy expenditure above the basal level. physical activity can be categorized into light, moderate, or heavy intensity as well as weekday and weekend activity, plus 
several other categories. [3]Many studies have shown that a regular physical activity increases thinking and learning skills. [1,2] Several hypothesis have described the mechanism of which physical activity could improve academic performance including increasing the blood and oxygen flow to the brain, increasing the levels of norepinephrine and endorphins, reduction of stress and improvement of mood $[4,5,6]$.

\section{Objectives:-}

The purpose of this study is to determine the percentage of students who are physically active and to find out whether physical activity has a beneficial effect on their academic performance or not.

\section{Literature Review:-}

Dawn Podulka Coe et al discussed the Effect of Physical Education and Activity Levels on Academic Achievement in Children. They enrolled 214 Participants who were sixth-grade students and randomly assigned to physical education during either first or second semesters. Academic achievement was assessed using grades from four core academic classes and standardized test scores. They found that Students who either performed some vigorous activity had significantly higher grades $(\mathrm{P}<0.05)$ than students who performed no vigorous activity in both semesters. [7]

Sigfúsdóttir ID, Kristjánsson AL .et al dicussed Health behaviour and academic achievement in Icelandic school children, a cross-sectional survey data from 5810 Icelandic school children. They found that the correlation between physical activity and grades is positive and significant $(\mathrm{P}<0.01)$ and findings are consistent with previous work and affirm the complexity of the relationship of health to academic achievement. [8]

Pei-An Liao1, Hung-Hao Chang et al. discussed Physical fitness and academic performance: empirical evidence from the National Administrative Senior High School Student Data in Taiwan. They used a dataset of 149240 university-bound senior high school students from 2009 to 2011 was constructed by merging two nationwide administrative datasets of physical fitness test performance and the university entrance exam scores. Using a Hierarchical linear regression models the study revealed An increase of 1 SD on students' overall physical fitness from the first to third school year is associated with an increase in the university entrance exam scores by 0.007 and $0.010 \mathrm{SD}$ for male and female students, respectively. [9]

\section{Material \& Method:-}

We distributed the questionnairetoallfirst, second, third and fourth year medical students of Imam university. We used the GPA and duration of daily studying to access the academic performance and we used thetype of physical activity and the duration these activities are to access the status of physical activity of each student. We collected back 103 questionnaires, 87 of them were complete and we excluded the 16 questionnaires that were incomplete. response rate was $18.5 \%$. we analyzed the data using SPSS.

\section{Result and Discussion:-}

Out of the 87 participant 48 student had a GPA of 3.00 to 3.99 which makes it the most common rang of GPA, followed by a GPA of 2.00 to 2.99 ( 20 students ). 17 student had a GPA between 4.00 to 5.00 (19.5\%) and only 2 student had a GPA of <2.00.[Table 1] [ chart 1]

29 students out of all participant were physically active, most of the student who were physically active had a GPA of 3.00 to 3.99 ( $62.1 \%$ ) followed by the students who scored a GPA of 4.00 to 5.00 (24.1\%). Then a GPA of 2.00 to $2.99(13.8 \%)$. None of the student who had a GPA of <2.00 were physically active.[Table 1] [ chart 2]

Cardiovascular-gym exercise and walking were the two most commonly performed type of physical activity ( $33.5 \%$ each ). Sports were the third most common physical activity (27.6\%). Only one student was performing weight lifting (3.4\%).[Table 1]

(75.0\%) of the physically active student with a GPA of 2.00 to 2.99 were walking, while only (25.0\%) performed cardiovascular-gym exercise. Among the physically active group of students who scored a GPA of 3.00 to 3.99 , thirty eight percent were performing sports, while (27.8\%) performed cardiovascular-gym exercise, 5 out of the 28 student who scored a GPA of 3.00 to 3.99 were walking (27.8\%). While only (14.3\%) of the physically active 
student with a GPA of 4.00 to 5.00 performed sports, (57.1\%) were performing cardiovascular-gym exercise and (28.6\%) were walking.[Table 1]

(50.0\%) of the physically active student who had a GPA of 2.00 to 2.99 spent more than 180 minuets/week in physical activity. Most of the physically active student with a GPA of 3.00-3.99 performed activity for more than 180 minutes weekly ( $38.9 \%$ ) and only (11.1\%) spent less than 60 minutes weekly.60 to 120 minutes weekly physical activity was the most common duration among the physically active student with a GPA of 4.00 to 5.00 (42.9\%), followed by more than 180 minutes per week (28.5\%). Among all student with different GPA more than 180 minutes of physical activity was the most common duration ( $37.9 \%)$ and less than 60 minutes was the least ( 10.3\%).[Table 1]

All student with a GPA of less than 2.00 spent less than 60 minutes of daily studying. (90.0\%) of the students with a GPA of 2.00 to 2.99 studied for less than 60 minutes daily and only (10.0\%) studied for 60 to 120 minutes per day. Most of the students with a GPA of 3.00 to 3.99 spent 60 to 120 minutes studying daily (66.6\%), (29.2\%) studied for less than 60 minutes daily and only 1 student studied for more than 180 minutes per day. 60 to 120 minutes and 120 to 180 minutes of daily studying were the two most common duration that was spent by students who has a GPA of 4.00 to 5.00 ( $41.2 \%$ each ) followed by less than 60 minutes studying per day ( $11.7 \%$ ), and only (5.9\%) studied for more than 180 minutes daily. Among all the students 60 to 120 minutes was the most common duration of studying ( $49.4 \%$ ) followed by less than 60 minutes of studying daily (39.0\%). Nine percent of the students studied for 120 to 180 minutes, and only (2.3\%) studied for more than 180 minutes daily.[Table 1]

We found that there was an association between physical activity and academic performance with astatistical trend toward significance $(\mathrm{p}$ value $=0.09)$.

Table 1:- Characteristics of medical students of Imam university

\begin{tabular}{|c|c|c|c|c|c|c|}
\hline & \multicolumn{5}{|l|}{ GPA } \\
\hline & & $<2.00$ & $2.00-2.99$ & $3.00-3.99$ & $4.0-5.0$ & total \\
\hline \multicolumn{2}{|l|}{ Number of participant } & 2 & 20 & 48 & 17 & 87 \\
\hline \multicolumn{2}{|l|}{ Physically active } & 0 & $\begin{array}{l}4 \\
(13.8 \%)\end{array}$ & $\begin{array}{l}18 \\
(62.0 \%)\end{array}$ & $\begin{array}{l}7 \\
(24.1 \%)\end{array}$ & 29 \\
\hline \multicolumn{2}{|l|}{ Non- Physically active } & $\begin{array}{l}2 \\
(3.4 \%)\end{array}$ & $\begin{array}{l}16 \\
(27.5 \%)\end{array}$ & $\begin{array}{l}30 \\
(51.7 \%)\end{array}$ & $\begin{array}{l}10 \\
(17.2 \%)\end{array}$ & 58 \\
\hline \multirow{4}{*}{ Type of activity } & $\begin{array}{l}\text { Cardiovascular-Gym } \\
\text { exercise * }\end{array}$ & 0 & $\begin{array}{l}1 \\
(10.0 \%)\end{array}$ & $\begin{array}{l}5 \\
(50.0 \%)\end{array}$ & $\begin{array}{l}4 \\
(40.0 \%)\end{array}$ & 10 \\
\hline & Walking & 0 & $\begin{array}{l}3 \\
(30.0 \%) \\
\end{array}$ & $\begin{array}{l}5 \\
(50.0 \%) \\
\end{array}$ & $\begin{array}{l}2 \\
(20.0 \%) \\
\end{array}$ & 10 \\
\hline & Sports** & 0 & 0 & $\begin{array}{l}7 \\
(87.5 \%) \\
\end{array}$ & $\begin{array}{l}1 \\
(12.5 \%) \\
\end{array}$ & 8 \\
\hline & Weight lifting & 0 & 0 & $\begin{array}{l}1 \\
(100.0 \%)\end{array}$ & 0 & 1 \\
\hline \multirow{4}{*}{ Duration of activity } & $<60$ minutes/week & 0 & $\begin{array}{l}1 \\
(33.3 \%)\end{array}$ & $\begin{array}{l}2 \\
(66.6 \%)\end{array}$ & $\begin{array}{l}1 \\
(33.3 \%)\end{array}$ & 4 \\
\hline & 60-120 minutes/week & 0 & 0 & $\begin{array}{l}5 \\
(62.5 \%)\end{array}$ & $\begin{array}{l}3 \\
(37.5 \%)\end{array}$ & 8 \\
\hline & 120-180 minutes/week & 0 & $\begin{array}{l}1 \\
(16.6 \%)\end{array}$ & $\begin{array}{l}4 \\
(66.6 \%)\end{array}$ & $\begin{array}{l}1 \\
(16.6 \%)\end{array}$ & 6 \\
\hline & $>180$ minutes/week & 0 & $\begin{array}{l}2 \\
(18.1 \%)\end{array}$ & $\begin{array}{l}7 \\
(63.6 \%)\end{array}$ & $\begin{array}{l}2 \\
(18.1 \%)\end{array}$ & 11 \\
\hline \multirow{4}{*}{ Duration of studying } & $<60$ minutes/day & $\begin{array}{l}2 \\
(5.9 \%)\end{array}$ & $\begin{array}{l}18 \\
(52.9 \%)\end{array}$ & $\begin{array}{l}14 \\
(41.1 \%)\end{array}$ & $\begin{array}{l}2 \\
(5.9 \%)\end{array}$ & 36 \\
\hline & 60-120 minutes/day & 0 & $\begin{array}{l}2 \\
(4.8 \%)\end{array}$ & $\begin{array}{l}32 \\
(78.0 \%)\end{array}$ & $\begin{array}{l}7 \\
(17.0 \%)\end{array}$ & 41 \\
\hline & $120-180$ minutes/day & 0 & 0 & $\begin{array}{l}1 \\
(12.5 \%)\end{array}$ & $\begin{array}{l}7 \\
(87.5 \%)\end{array}$ & 8 \\
\hline & $>180$ minutes/day & 0 & 0 & $\begin{array}{l}1 \\
(50.0 \%)\end{array}$ & $\begin{array}{l}1 \\
(50.0 \%)\end{array}$ & 2 \\
\hline
\end{tabular}


(*) for example : Elliptical, Treadmill, Stationary Bike ... etc.

$(* *)$ for example : Football, basketball, volleyball... etc.

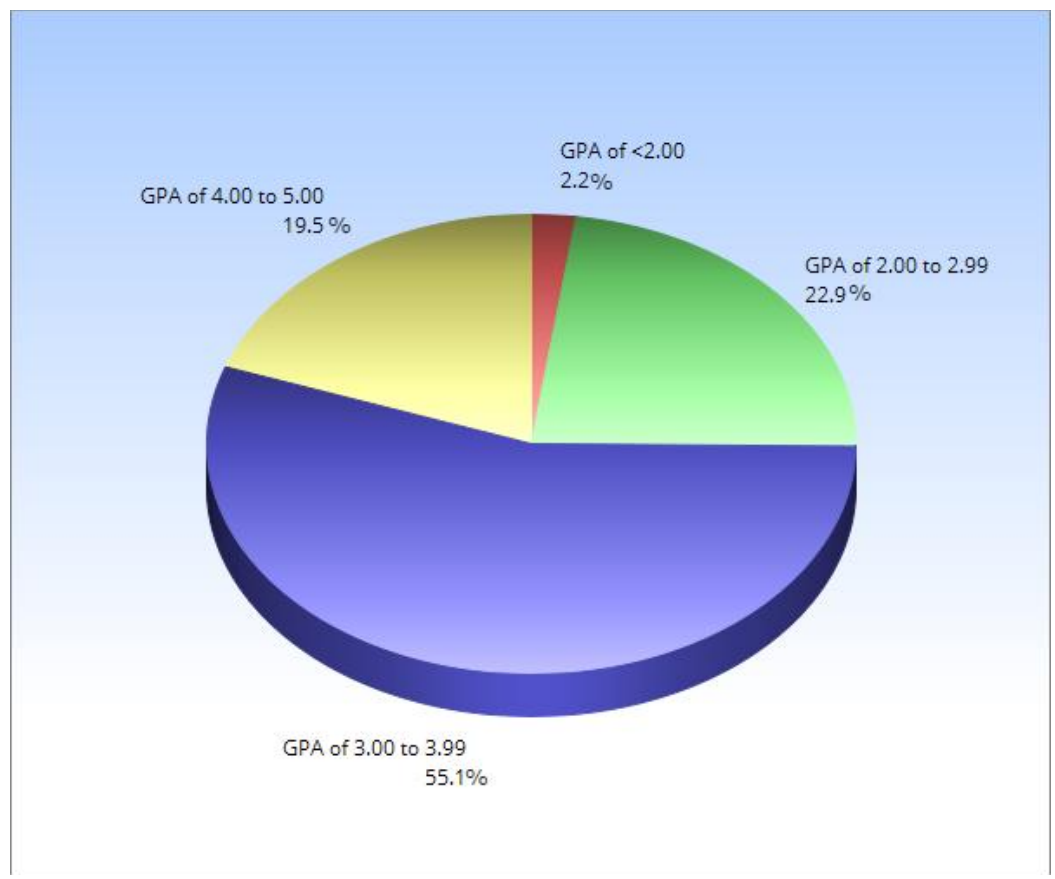

Chart 1:- GPAs of medical students of Imam university.

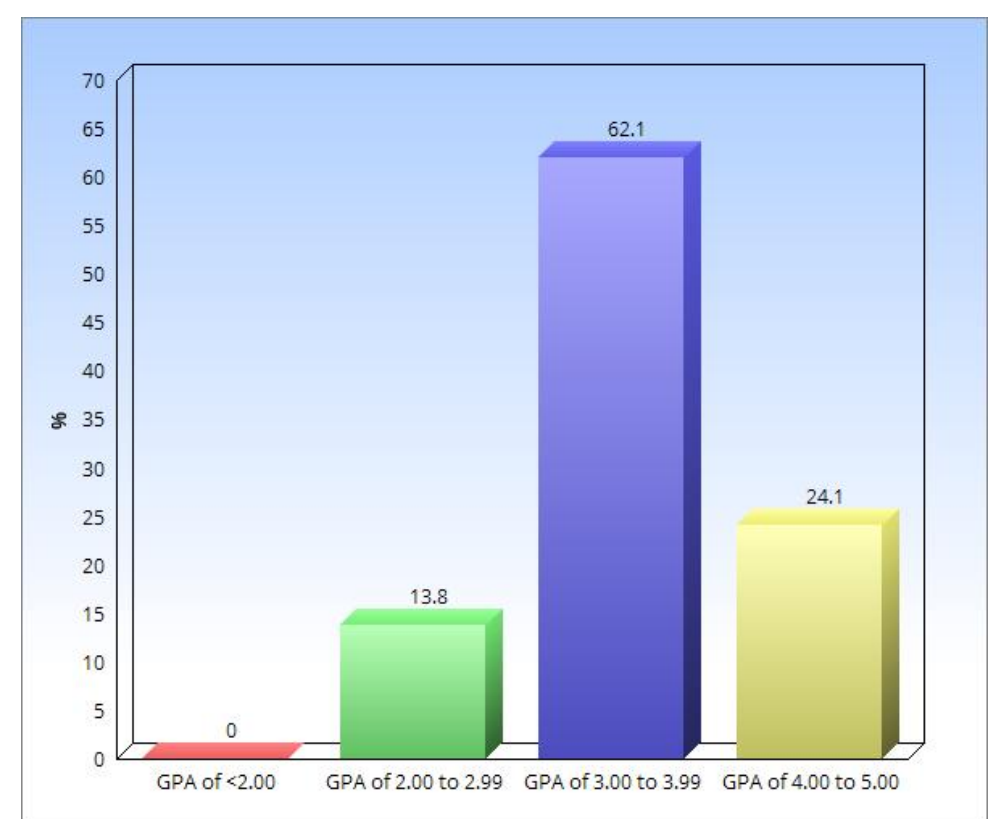

Chart 2:- GPAs of physically active medical students of imam university( percentage )

\section{Conclusion:-}

In this study we found a difference in the GPA of the students of Imam university according to their physical activity status with a statistical trend toward significance ( $\mathrm{p}$ value $=0.09$ ). We recommend doing a similar study on a larger scale to determine the effect of physical activity on academic performance in the Kingdom of Saudi Arabia.

\section{Acknowledgement:-}

We would like to thank Dr. Abdullah Alrabia for guiding and supervising our research. 


\section{References:-}

1. Centers for Disease Control and Prevention. Physical Activity and Health Web Sites, at: http://www.cdc.gov/physicalactivity/everyone/health/index.html. Accessed: 10 March 2013.

2. United States Surgeon General's report on physical activity and health. From the Centers for Disease Control and Prevention.1996.

3. Caspersen C, Powell K, Christenson G. Physical activity, exercise and physical fitness: Definitions and distinctions for health-related research. Public Health Rep. 1985;100:126-31.

4. Penedo FJ, Dahn JR. Exercise and well-being: a review of mental and physicalhealth benefits associated with physical activity. CurrOpin Psychiatry. 2005;18(2):189-193.

5. Hillman $\mathrm{CH}$, Erickson KI, Kramer AF. Be smart, exercise your heart: exercise effectson brain and cognition. Nat Rev Neurosci. 2008;9(1):58-65.

6. Jorgensen LG, Nowak M, Ide K, Secher NH. Cerebral blood flow and metabolism.In: Saltin B, Boushel R, Secher N, Mitchell J, eds. Exercise and Circulation in Health and Disease. Champaign, IL: Human Kinetics Publishers; 2000:113-236.

7. Dawn Podulka Coe et al. the Effect of Physical Education and ActivityLevels on Academic Achievement in Children.MedSci Sports Exerc.2006 Aug;38(8):1515-9.

8. Sigfúsdóttir ID, Kristjánsson AL et al. Health behaviour and academic achievement in Icelandic school children. Health Educ Res. 2007 Feb;22(1):70-80. Epub 2006 Jun 9.

9. Pei-An Liao1, Hung-Hao Chang et al. Physical fitness and academic performance: empirical evidence from the National Administrative Senior High School Student Data in Taiwan. Health Educ. Res. (2013) doi: 10.1093/her/cyt041 